\title{
THE DETECTION OF ATMOSPHERIC WAVES PRODUCED BY THE TOTAL SOLAR ECLIPSE OF 11 AUGUST 1999
}

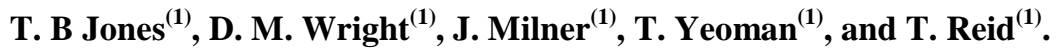 \\ (1) Dept. of Physics and Astronomy, University of Leicester, University Road, Leicester, LE1 7RH.( UK) \\ (tbj@ion.le.ac.uk) \\ A. Senior ${ }^{(2)}$ and P. Martinez ${ }^{(2)}$ \\ ${ }^{(2)}$ Dept. of Communications Systems, Lancaster University, Lancaster, LA1 4YR, (UK)
}

\begin{abstract}
Previous attempts to detect Eclipse-induced acoustic gravity waves (AGWs) have met with varying degrees of success. In this study the speed and direction of the waves have been determined at two widely spaced locations by an HF Doppler technique. The AGW activity following the eclipse was different to the background waves detected before the event in amplitude, speed and direction. The velocity vectors are consistent with a generating mechanism for the waves based on the supersonic passage of the cooled region of the atmosphere during the eclipse.
\end{abstract}

\section{INTRODUCTION}

During a total solar eclipse, the super-sonic movement of the cooled spot in the ozone layer produced by the moon's shadow, can lead to the production of internal atmospheric gravity waves, [1]. Experimental observations of these waves have not been conclusive, although several authors have reported wave activity, [2], [3], [4]. The atmospheric waves propagate upwards and outwards from the source region and at ionospheric heights, produce travelling ionospheric disturbances (TIDs). These can be detected by radio reflection techniques and their speed and direction measured by triangulation, [5[, [6]. During the total eclipse of 11 August 1999, a series of specially designed experiments were undertaken in the UK which were optimised to detect any waves produced at ionospheric heights by the passage of the cooled region of the atmosphere.

\section{EXPERIMENTAL RESULTS.}

The speed and direction of the AGWs were measured by means of a four station Doppler experiment operating on a frequency of $5.750 \mathrm{MHz}$. The transmitters, which had frequency offsets of 3, 6, 9 and $12 \mathrm{~Hz}$, were situated at Aberystwyth, Lancaster, Southampton and St. Erme respectively, all at distances of approximately $150 \mathrm{~km}$ from the central receiver located at Leicester. In addition, Doppler measurements were made at $3.579 \mathrm{MHz}$ on the short (50 km) path from Ergemont to Kendal and at $11.117 \mathrm{MHz}$ over the long (1500km) path from Uppsala, Sweden to Leicester.

\section{a) Four Station, 5.750 MHz Doppler experiment.}

The time variation of the frequencies of the four station Doppler experiment for the eclipse period, 06.00 to 14.00 UT on the 11 August 1999, is reproduced in Fig. 1 and the four transmitters can be clearly identified by their frequency offsets. Wave activity is present to some extent throughout the interval. At the start of the eclipse, first contact was at 08.57 UT at St Erme, the four frequencies begin to move increasingly negative reaching minimum values at approximately 09.55 UT. This corresponds to the period when the sun's ionising radiations are progressively cut off by the moon's shadow. The flux of the ionising radiations decreases and consequently the electron density in the ionosphere is depleted, causing the reflection points to move upwards. After 09.58 UT the frequency moves rapidly back towards the pre eclipse (zero displacement) value, which is reached at about 10.05 UT. At this time, the greatest reduction in the electron density due to the eclipse has been reached and the reflection points have stopped moving yielding a zero Doppler shift. After this time, the sun's ionising radiations start to illuminate the atmosphere, electron production increases and a positive Doppler shift (lower reflection heights) is apparent. The maximum positive Doppler occurs at 10.30 UT when the reflection heights are descending and the electron density is increasing most rapidly. The frequencies have returned to their unperturbed values by 11.35 UT when the eclipse-induced changes have ended. 


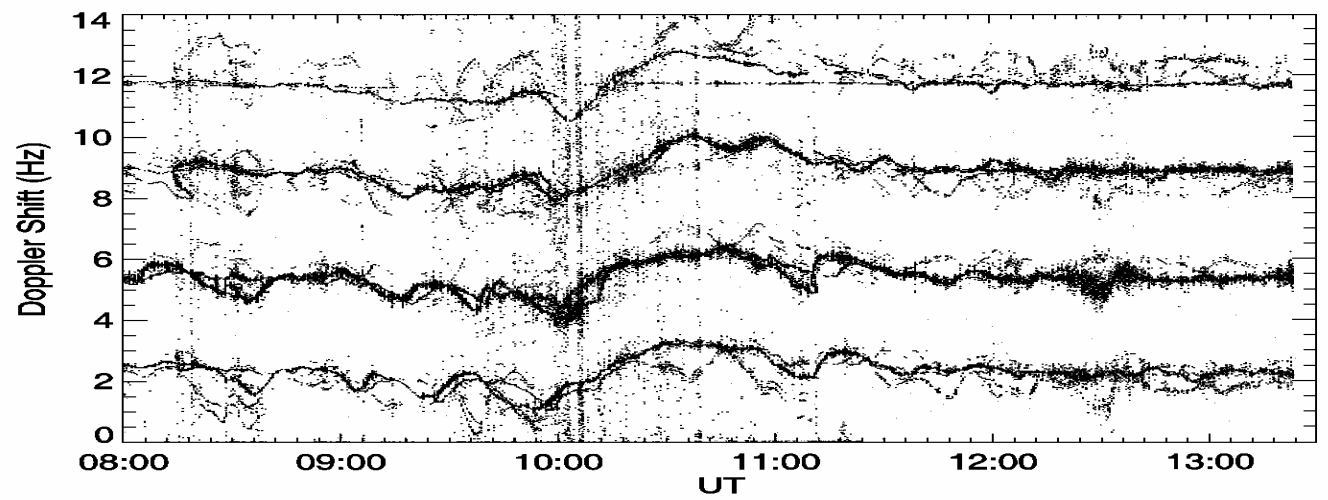

Fig 1. Wave activity detected by the $5.750 \mathrm{MHz}$ four station Doppler experiment during the Eclipse period, 11 August 1999.

The fourth contact at St. Erme was at 11.32 UT. The entire period is characterised by considerable wave (TID) activity, which makes it difficult to resolve the eclipse induced waves from the background. However, particularly large waves are evident during the eclipse at 09.50 UT and at 11.00 UT.

b) Doppler measurements at 3.759 MHz, Egremont to Kendal, (50km) path and the $11.117 \mathrm{MHz}$, Uppsala to Leicester, $(1400 \mathrm{~km})$ path.

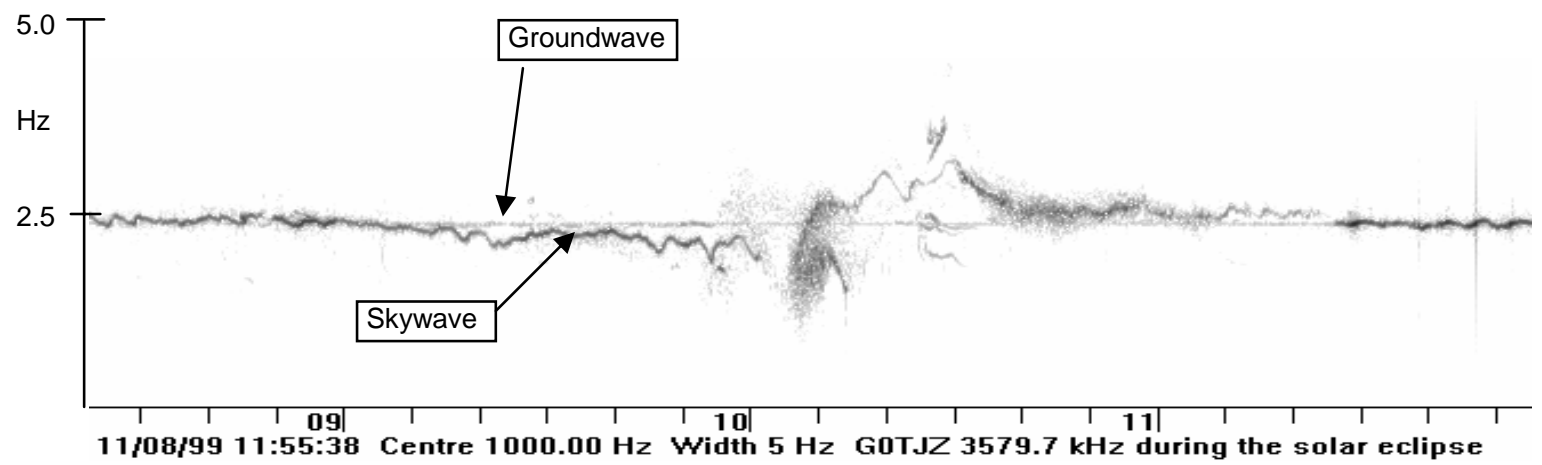

Fig 2. Doppler frequency changes observed on the $3.579 \mathrm{MHz}$ signal from Eregmont to Kendal, Cumbria (50 km path) during the Eclipse period, 11 August 1999.

The recording of frequency against time for the 3.579 MHz Doppler experiment is reproduced in Fig.2. The wave amplitudes are much smaller $(\sim 0.5 \mathrm{~Hz})$ than for the F region case of Fig $1(\sim 1.5 \mathrm{~Hz})$. This is to be expected because of the frequency difference and the exponential decrease in atmospheric density with height producing a corresponding increase in AGW amplitude. Background wave activity is present before the eclipse but the wave amplitudes increase significantly after the time of totality when the Doppler displacement passes through the unperturbed value at 10.10 UT. In contrast to the four station data, there is considerably less wave activity before totality at these lower heights, although strong wave features are present after this time. Reference to ionograms indicates that mode changes between F1 and Es layers occur at the time of totality, which account for the spread nature of the signal frequency at this time. For most of the event this signal is reflected from an equivalent height of about $200 \mathrm{~km}$ in the F1 region.

In order to provide a widely spaced monitoring point, the frequency of the $11.117 \mathrm{MHz}$ transmission from Uppsala, Sweden, was monitored at Leicester, (see Fig 3.). The long period changes are clear and similar to those observed for the other Doppler experiments. Although there is continuous wave activity throughout the observing interval, a very large frequency disturbance occurs at 11.00 UT just after the time of totality, which is probably associated with the passage of a shock front. 


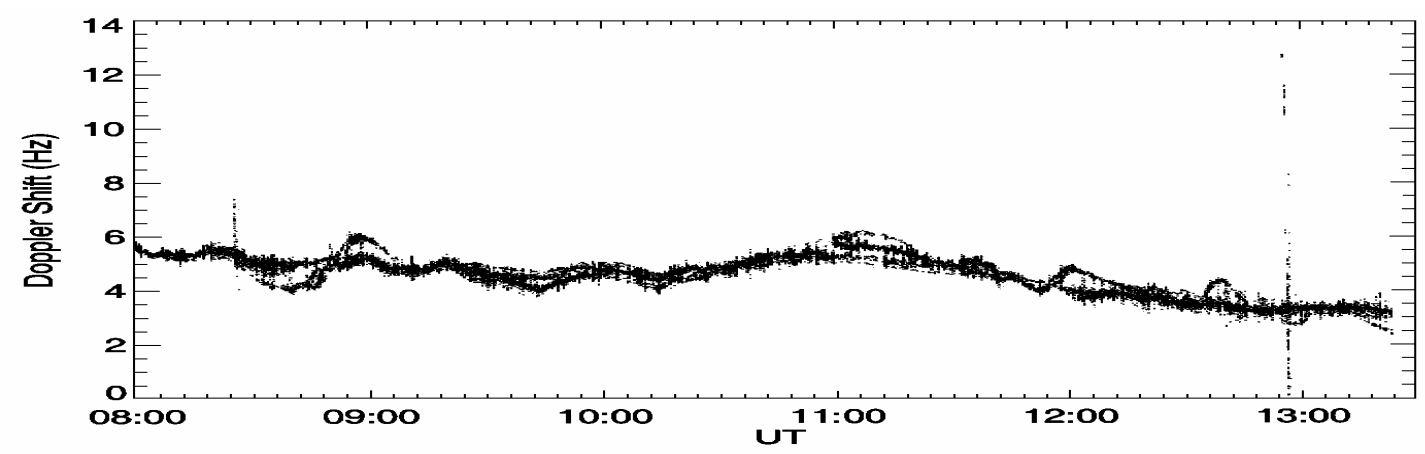

Fig 3. Doppler frequency changes observed on the $11.117 \mathrm{MHz}$ transmission from Uppsala to Leicester (1400 km path) during the Eclipse period, 11 August 1999.

\section{Discussion and Conclusions}

The long period changes in electron density produced by the variations in the flux of the solar ionizing radiations, [7], [8], will not be discussed further here. The wave activity is associated with the movement of the terminator which produces internal acoustic gravity waves with periods ranging from about 10 to 100 minutes. The Doppler records suggest that both long and short period waves are present. To distinguish between these waves, the data were filtered with, a) a low pass filter with a cut off period of $40 \mathrm{~min}$, and b) a filter with a pass band of 10 to $40 \mathrm{~min}$. From the filtered data, the time difference of the wave signatures at the four reflection points has been determined by cross correlation. From these time shifts and a knowledge of the locations of the reflection points, the speed and direction of the waves have been determined. Data from all four paths were used in the analysis.

For waves of both period ranges, there is a significant difference both in speed and direction after the passage of the totality zone through the observing area. Before totality, the waves appear to be travelling from NW to SE with speeds of about $150 \mathrm{~m} / \mathrm{s}$. This is typical AGW behaviour for this time of day at these latitudes. Following the passage of totality the speed of the waves is slightly reduced but there is a very significant change in their direction. All the waves, irrespective of their period, now propagate from SE to NW, the direction that would be expected if the source region was in the zone of totality. There is some evidence that the wave direction moves progressively eastwards as the region of totality moves away from the measuring array.

The wave generation and propagation cannot be represented by a simple model, however, it is instructive to consider a point source of AGWs moving at supersonic speeds along the line of totality. The positions of the wave fronts emitted by such a source moving at $667 \mathrm{~m} / \mathrm{s}$ emitting a wave of speed $200 \mathrm{~m} / \mathrm{s}$ at $2 \mathrm{sec}$ intervals as it travels from left to right along the x-direction, are shown in Fig. 4. The presence of a shock front and of travelling waves within the shock cone, are clearly evident. Since the observing array is some distance $(\sim 200 \mathrm{~km})$ from the line of totality, the figure indicates that the following sequence should occur. Shortly after the passage of the totality region the shock front should arrive at the monitoring point. This corresponds to the large wave structure present on the Doppler record at 10.00 UT. Following this, the wave fronts of the AGWs arrive, first in a direction perpendicular to the line of totality. As time progresses and the wave fronts expand, the direction of the wave front turns progressively eastwards and this behaviour is evident in the data. Although the model is oversimplified it does reproduce the basic characteristics of the waves observed. A fully coupled thermosphere-ionosphere model, e.g. CTIP, [9], is required.

The $3.759 \mathrm{MHz}$ signal received over the $50 \mathrm{~km}$ path from Egremont to Kendal has its reflection point in the F1 layer for most of the eclipse period and provides a monitor of the wave activity at heights much lower than those of the four station Doppler experiment. Cross-correlation of the 3.759 and the $5.750 \mathrm{MHz}$ signal received over the Lancaster to Leicester (L-L) path yield values of 0.59 and 0.87 for the pre- and post-totality periods respectively. This again confirms that the waves present after totality are well correlated and are present in both the upper and lower thermosphere, whereas those before totality are much more random. The wave signatures on the L-L path lead those on the Kendal path by about $60 \mathrm{sec}$. This is to be expected if the source is in the line of totality, since the vertical phase fronts of AGWs are tilted forwards in the direction of propagation, [5].

The reflection point of the Uppsala to Leicester (U-L) $11.117 \mathrm{MHz}$ transmission is located approximately $750 \mathrm{~km}$ NE of the four station $5.750 \mathrm{MHz}$ array. The wave activity has been cross correlated with that observed on the Lancaster to Leicester (L-L) path and by time shifting the data to obtain the highest correlation coefficient, the delay between the 


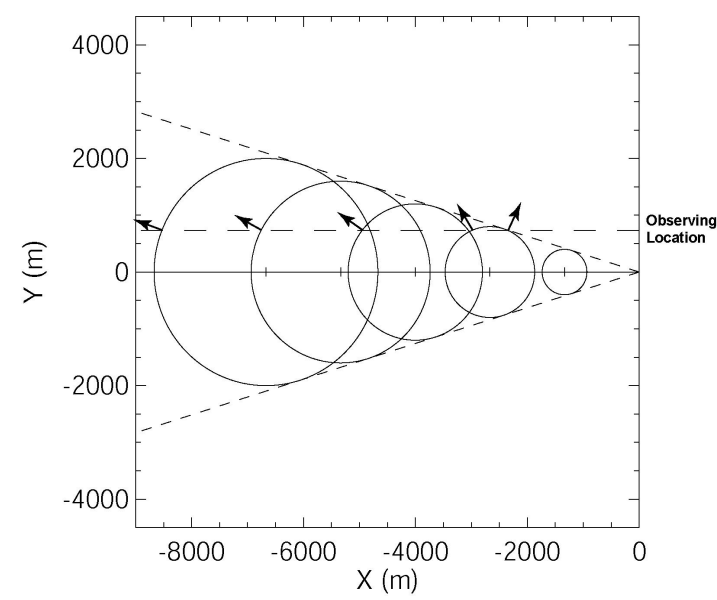

Fig 4. Model of a point source of waves of speed $200 \mathrm{~m} / \mathrm{s}$, moving along the $x$ direction at a speed of $667 \mathrm{~m} / \mathrm{s}$. The positions of the wave front are shown at $2 \mathrm{sec}$ intervals.

waves at the two locations can be obtained. The maximum values of the correlation coefficients were 0.7 and 0.9 for the pre and post totality periods respectively. These values correspond to the U-L waves leading the L-L waves by 12 min $30 \mathrm{sec}$ pre totality and post totality the L-L waves leading those on the U-L path by $43 \mathrm{~min}$ and 30 sec. The correlation coefficients confirm that the post eclipse waves are coherent over a long distance $(\sim 450 \mathrm{~km})$ whereas those observed before totality are more random. There is a time shift of $12 \mathrm{~min} 30 \mathrm{sec}$ between the waves observed on this path and those of the L-L path pre totality. This indicates has a southerly component wave velocity although it is not possible to determine the velocity vector from only two observing points. Post totality, the correlation is much higher and yields quite different time differences. In this case the waves are seen first on the L-L path and 43 min 30 sec later on the Uppsala path, corresponding to a velocity vector with a northward component. Assuming the waves travel with a velocity of $150 \mathrm{~m} / \mathrm{s}$ (a typical value from the four station Doppler array) then the time difference for the wave to travel between the reflection points of the L-L and U-L path is $50 \mathrm{~min}$, which is in close agreement with the measured value. For the post totality waves, these observations are consistent with a source region moving along the line of totality and the waves propagating N-E from sources along this line.

\section{REFERENCES}

[1] Chimonas G. and C. O. Hines, Atmospheric gravity waves induced by a Solar Eclipse, J. Geophys. Res., 75, 875, 1970 .

[2] Bertin K., F. A. Hughes and L. Kersley, Atmospheric waves induced by the Solar Eclipse of 30 June 1973, J. Atmos. Terr. Phys., 39, 457, 1977.

[3] Butcher E. C., A. M. Downing and K. D. Cole, Wavelike variations in the F-region in the path of totality of the eclipse of 23 October 1976, J. Atmos. Terr. Phys., 41, 439, 1979.

[4] Huang Y. N. and K. Chen, Ionospheric effects of the Solar Eclipse of September 231987 around the equatorial crest region. J. Geophys. Res., 97, 103-111, 1992.

[5] Georges T. M, Ionospheric effects of Atmospheric waves. ESSA Technical Report, IER 57-ITSA 54, US Dept of Commerce, 1967.

[6] Waldock J. A. and T. B. Jones, HF Doppler Observations of medium scale travelling ionospheric disturbances at mid-latitudes. J. Atmos. Terr. Phys., 48, 245-260, 1986.

[7] Salah J. E., W. L. Oliver, J. C. Foster, J. M. Holt, B. A. Emery and R. G. Roble., Obesrvations of the May 30 Annular solar eclipse at Millstone Hill. J. Geophys. Res., 91, 1651-1660, 1986.

[8] Roble R. G., B. A. Emery and E. C. Ridley, Ionospheric and Thermospheric response over Millstone Hill to the 30 May 1984 annular solar eclipse. J. Geophys. Res., 91 1661-1670, 1986.

[9] Fuller-Rowell T. J., D. Rees, S. Quegan, R. J. Moffett, M. V. Codrescu and G.H. Millward, A coupled IonoshereThermosphere Model (CTIM). Soar Terrestrial Energy Program (STEP) Handbook, ed. R. W. Schunk, pp 217-238, 1996. 